\title{
Unintended Consequences of Court Arbitration: A Cautionary Tale From New Jersey
}

\author{
Robert J. MacCoun*
}

Abitration programs are expected to reduce delay and costs by providing a more efficient substitute for trial. But since most disputes are already resolved without adjudication, an arbitration program is likely to divert more cases from settlement than from trial. The net effect can be an increase in delay and congestion in the courts. This pattern is illustrated by a recent study of court-annexed automobile arbitration in New Jersey. Following the introduction of arbitration, there was a significant reduction in the percentage of cases settled without third-party intervention, but no reliable decrease in the trial rate, and a significant increase in filing-to-termination time for auto cases assigned to the program. Arbitration programs appear to meet a demand for fair, adjudicative third-party hearings, but in doing so, they don't always improve court efficiency, and can even reduce it.

As the articles in this issue of Justice System Joumal attest, arbitration has become one of the most popular alternative dispute resolution (ADR) procedures for combatting the rising delays and costs associated with civil litigation (see MacCoun, Lind, and Tyler, forthcoming). Because trials are demonstrably the major source of congestion in the civil courts, there is a natural tendency to use resolution by trial as the baseline against which to evaluate resolution by arbitration and other ADR procedures. Arbitration programs are expected to reduce delay and costs to the extent that they divert disputes from proceeding to trial.

At the level of the individual case, this counterfactual reasoning-"how much more time and effort would a trial have consumed in this case?"-casts arbitration in a favorable light. By design, arbitration hearings minimize or eliminate many of the most time-consuming and expensive attributes of trial, including jury selection, expert and eyewitness testimony, and prolonged discovery activity. So it seems plausible to expect that an arbitration program might greatly expedite a court's civil caseload.

\footnotetext{
- Behavioral Scientist, Institute for Civil Justice, The RAND Corporation, Santa Monica, California.
}

THE JUSTICE SYSTEM JOURNAL, Volume 14, Number 2 (1991) 
But this line of reasoning overlooks the potential aggregate effects of introducing an arbitration program into the disputing environment. To understand this point, one must remember that the vast majority of civil disputes are resolved privately without trial-either through bilateral settlement negotiations ${ }^{1}$ or through the unilateral decision to "lump it" and refrain from disputing (Hensler et al., 1991; Trubek et al., 1983). But arbitration programs offer these disputants an opportunity to resolve their case using what is generally perceived to be a fair and satisfactory procedure (e.g., Adler, Hensler, and Nelson, 1983; Clarke et al., 1989b; Lind, 1990; Lind et al., 1989; MacCoun et al., 1988), with many of the same qualities that litigants value in trials (Lind et al., 1989), but without some the most inefficient attributes of trials. Moreover, since court arbitration is non-binding, litigants can use the service without jeopardizing their options for a trial de novo or a settlement on their own terms.

Because arbitration can be an attractive option for litigants, it may indeed divert some litigants from the trial calendar. But it will also keep litigants in the system who otherwise would have settled their cases without a trial, and there are likely to be many more litigants in this latter category. Furthermore, arbitration may attract defendants who otherwise would have settled the plaintiffs claim without filing an answer. Thus, arbitration is likely to divert many more cases from settlement than from trial. The net effect can actually result in an increase in delay and congestion in the courts. In this article, I will provide empirical support for this argument, drawing on recent research my colleagues and I have conducted at the Institute for Civil Justice, in particular, our recent evaluation of New Jersey's Automobile Arbitration Program. ${ }^{2}$

\footnotetext{
1 In this article, the term "bilateral settlement" refers to the private resolution of a case without a third-party hearing. Thus, settlements after an arbitration hearing or during a trial would not be included in this definition.

2 Our evaluation of the New Jersey program is described at length in the project's final report, from which some material in this article has been excerpted (MacCoun et al., 1988). I am grateful to my collaborators Allan Lind, Debby Hensler, David Bryant, and Pat Ebener, and to Robert Lipscher, Jane Castner, and their colleagues at the Administrative Office of the New Jersey Courts for their cooperation in the research.
} 


\section{The New Jersey Automobile Arbitration Program}

The New Jersey Automobile Arbitration Program was initiated by the state legislature in 1983 and implemented statewide in 1985 . The statute mandates arbitration for all automobile negligence disputes in which damages for personal injuries do not exceed $\$ 15,000$; the courts presume that this criterion is met if total medical expenses do not exceed $\$ 2,500$. Hearings must occur no earlier than 160 days after the service, and discovery must be completed within 150 days. Retired judges and experienced personal injury attorneys serve as arbitrators and receive a per diem fee of $\$ 125$ to $\$ 250$ depending on the size of the panel. The rules of evidence are relaxed in hearings, and depositions and other forms of paper evidence generally replace oral testimony. The arbitration hearings are scheduled by the court staff and conducted in court facilities, and attorneys and parties are required to attend. The arbitration award must be filed within ten days of the hearing. The parties have $\mathbf{3 0}$ days in which to file a demand for trial de novo, and there are modest financial penalties for rejecting the award. There are some local variations across courts in the implementation of the program; e.g., use of single arbitrators vs. two-arbitrator panels, scheduling of trials de novo on an accelerated vs. case-age basis, and automatic assignment of auto negligence filings to the program (with an "opt-out" option) vs. prescreening for eligibility. ${ }^{3}$

\section{Approach to Evaluation}

The Administrative Office of the New Jersey Courts asked the Institute for Civil Justice to conduct an empirical evaluation of the new program, and our evaluation began in 1986. Our methodology is described in detail in MacCoun et al. (1988) and will only be summarized here. We randomly sampled more than 1,000 auto negligence cases filed in eight New Jersey courts in the second half of 1983 (before the program's inception) and the second half of $1985^{4}$ The latter included cases assigned to arbitration as well as cases that were not. We sampled cases by the

\footnotetext{
3 This is a description of the program during the period of our evaluation (1983 to 1986) and may not characterize its more recent implementation.

4 Selecting optimal sample periods is difficult. The earlier the prearbitration period, the more difficult it becomes to retrieve the relevant data; the later the postarbitration period, the more difficult it becomes to find cases that have terminated by the time the data are collected. Moreover, the longer the gap between the periods, the greater the risk that other intervening events will obscure the unique effects of the arbitration program. However, focusing on the first year of a new program may also have distorting effects; most programs become more efficient once new administ rative procedures are institutionalized and start-up problems are resolved.
} 
date at which they were filed (rather than the date at which they were arbitrated or terminated) because this strategy allowed us to examine whether a change in the litigation environment provided by the courts-the arbitration program-influenced the manner in which cases were litigated from the day that they were filed. We oversampled 1985 cases relative to 1983 cases, and answered cases relative to unanswered cases, in order to have an adequate number of arbitrated cases in our sample. For each case sampled, we abstracted data from local court records and surveyed attorneys by mail. 5 From each court record, we abstracted information about the parties to the case, case processing dates and events, arbitration processing dates, the arbitration outcome, and the final status of the case. Table 1 presents the number of abstracted cases per county per period.

\section{Caveats}

While the pre-post research design that we adopted is preferable to the post-test only strategy that is common in court program evaluation, it nevertheless precludes strong inferences regarding cause and effect. In our evaluation, differences in disposition patterns between cases filed in 1983 and cases filed in 1985 might be caused by the arbitration program, or they might result from other changes in the litigation environment in New Jersey during this two-year period. To some extent, we compensate for this limitation by reporting litigation statistics (e.g., trial rates) as a percentage of total filings, which controls for any changes in total caseload, and also by comparing assigned vs. unassigned cases within the postarbitration period. There is an alternative methodology that would have permitted stronger causal inferences: a controlled experiment in which cases would be randomly assigned at filing to either arbitration or a nonarbitration control group, but this type of design was not logistically feasible for our evaluation. ${ }^{6}$

\footnotetext{
5 We also surveyed approximately 300 litigants and 400 attorneys immediately after their arbitration hearings to assess their evaluation of the hearing process and the arbitration outcome. In the present article, I will rely primarily on the case abstraction data; the results of the other data sets are presented in MacCoun et al. (1988).

6 Even in randomized field experiments, the decision by litigants to drop or settle their cases privately can result in differential attrition across conditions, thereby undermining some of the inferential advantages of random assignment (MacCoun, Lind, and Tyler, forthcoming).
} 
Table 1.

Sampling of Auto Negligence Filing

\begin{tabular}{|c|c|c|c|c|}
\hline \multirow[b]{2}{*}{ Court } & \multicolumn{2}{|c|}{$\begin{array}{c}\text { Prearbitration } \\
\text { July } 1 \text {-Dec. } 31,1983\end{array}$} & \multicolumn{2}{|c|}{$\begin{array}{c}\text { Postarbitration } \\
\text { July } 1-\text { Dec. } 31,1985\end{array}$} \\
\hline & $\begin{array}{l}\text { Total } \\
\text { filings }\end{array}$ & $\begin{array}{c}\text { Cases } \\
\text { abstracted }\end{array}$ & $\begin{array}{r}\text { Total } \\
\text { filings }\end{array}$ & $\begin{array}{c}\text { Cases } \\
\text { abstracted }\end{array}$ \\
\hline Atlantic/Cape May & 106 & 18 & 164 & 30 \\
\hline Camden & 181 & 27 & 380 & 75 \\
\hline Hudson & 180 & 23 & 344 & 58 \\
\hline Mercer & 354 & 109 & 622 & 152 \\
\hline Middlesex & 227 & 36 & 484 & 119 \\
\hline Monmouth & 145 & 52 & 253 & 142 \\
\hline Morris & 52 & 7 & 91 & 33 \\
\hline Passaic & 166 & 28 & 351 & 96 \\
\hline Total & 1411 & 300 & 2689 & 705 \\
\hline
\end{tabular}

We believe that our evaluation provides a fairly accurate picture of litigation during the time periods we examined in the eight courts studied, but the degree to which our results characterize other arbitration programs, or the New Jersey program in subsequent years, is uncertain. Other recent studies, examining different arbitration programs and using different methodologies, support the interpretations offered here, and are cited where appropriate.

\section{Effects of the Arbitration Program on the Litigation Environment}

In this article, I will describe the effect that the New Jersey arbitration program appears to have had on the nature and timing of case dispositions, and on litigant and attorney satisfaction. MacCoun et al. (1988) describe additional findings of the evaluation, including effects on discovery activities, attorney hours and private costs. ${ }^{7}$

\footnotetext{
${ }^{7}$ In general, we found that cases assigned to the program required somewhat more activity- e.g., more interrogatories - than unassigned cases or prearbitration cases, but we did not detect any reliable differences in attorney hours or private costs. Limitations of our cost data are discussed in
} 
Movement of Cases Through the Program. Figure 1 shows the disposition of cases assigned to the program in the postarbitration period. About 68 percent of all auto negligence filings were assigned to the program. Among assigned cases, medical specials ranged from $\$ 23$ to $\$ 33,224$, with a median value of $\$ 2,350$; about 47 percent of the cases exceeded the $\$ 2,500$ threshold for eligibility. Courts that prescreened cases for eligibility assigned significantly fewer cases exceeding the medical-specials threshold to the program (19\%) than courts that did not $(49 \%)$ $\left[\mathrm{X}^{2}(1)=4.34, p<.05\right]$.

Slightly more than half of the assigned cases were actually heard by arbitrators. On average, these litigants waited about a year from the time the initial complaint was filed to get to a hearing; the median time was about 333 days. About a third of the cases either settled privately or were dismissed prior to a hearing. Note that some cases were still pending and may have been heard by arbitrators after we abstracted their case records. ${ }^{8}$

Litigants requested a trial de novo in just over half of the cases that were heard. Courts using prescreening received 24 percent fewer trial de novo requests than courts that did not $\left[\mathrm{X}^{2}(1)=4.83, p<.05\right.$.]. Approximately 40 percent of these requests were made by a plaintiff, 56 percent were made by a defendant, and the party making the request was not reported for the remaining four percent of the cases. The arbitration award was accepted in 21 percent of the cases, and an additional 17 percent were settled either at or after the hearing without a request for a trial de novo.

Arbitration awards were reported for 214 of the hearings in our 1985 sample. The arbitrators awarded the plaintiff or plaintiffs at least some money in 90 percent of these hearings; the mean award was $\$ 12,820$; and the median award was $\$ 9,000$. Taking into account the possibility of a defense verdict, the expected arbitration award for plaintiffs was $\$ 11,470$. Of the 138 cases for which a trial de novo was requested, almost half settled before trial began. Only ten percent

MacCoun et al. (1988).

8 The cases from our 1983 sample were abstracted an average of 46 months after they were initially filed with the courts, and all of those cases had terminated. By contrast, the cases from our 1985 sample were abstracted only 22 months after filing, on average, and 23 percent of these cases were still pending at the time we abstracted their court records. The minimum amount of time between filing and abstracting for our 1985 sample was 561 days (i.e., almost 19 months). Thus, in some of our analyses, we excluded prearbitration cases that had not terminated within 561 days to control for this difference. Later, I will refer to this as the adjusted samplecomparison. 
actually went to trial. ${ }^{9}$ This suggests that the parties may often use a trial request as a bargaining tactic for negotiating a more favorable settlement. ${ }^{10}$

Effects on the Answer Rate. Our first indication that the arbitration program might be diverting cases from private settlement comes from an examination of the percentage of filed cases that are contested by the defendant, the answer rate. We estimate that the answer rate was significantly larger in the postarbitration period $(56 \%)$ than in the prearbitration period $(42 \%)[z=2.10, p<.05] .^{11}$ While cur pre-post design does not allow us unambiguously to attribute this increase to the introduction of the arbitration program, cases randomly assigned to a federal arbitration program in a recent field experiment (Lind, 1990) were significantly more likely to be answered (70\%) than were cases randomly assigned to a control group (55\%). Thus it seems likely that the program has drawn disputes into the courts.

Effects on Trial Rates. There are two sets of trial rate estimates in Table 2; the first set is based on our total sample, while the second set adjusts for the pending cases in our postarbitration sample. In either case, we estimate a trial rate of only three to four percent in the prearbitration period. For the postarbitration period, we estimate a somewhat lower trial rate of about two percent; this slight difference is not statistically significant. Because trial rates were already so low, it is statistically very difficult to detect small decreases without a considerably larger and more expensive sample. ${ }^{12}$

\footnotetext{
9 Although only 14 of the cases in our sample resulted in a trial de novo, the New Jersey AOC began collecting data on de novo cases in 1986, and provided us with data from 289 auto cases tried between July 1986 and April 1988. In this sample, arbitration and trial verdicts were in agreement 68 percent of the time, but defense verdicts were more common at trial (48\%) than at arbitration (23\%) $\left[\mathrm{X}^{2}(1)=44.86, \mathrm{p}<.001\right)$. There was no statistically significant change in trial de novo awards relative to arbitration awards.

10 Consistent with this interpretation, 90 percent of the attorneys in our post-hearing survey believed that arbitration awards did influcnce settiements; 59 percent believed that the award "provides a useful starting point for negotiations."

11 Since only answered cases were assigned to the program, we cannot compare the answer rate for assigned and unassigned cases in the postarbitration period.

12 Our sample size was adequate for the detection of relatively small effects, but we estimate that we would require a threefold increase in sample size to have a reasonable ( $80 \%)$ likelihood of concluding that a reduction of less than 2 percent was statistically significant. This conclusion is based on statistical power analyses presented in MacCoun et al. (1988; see Cohen, 1988). The lack of statistical significance means that the apparent difference in Table 2 might be due to sampling error.
} 


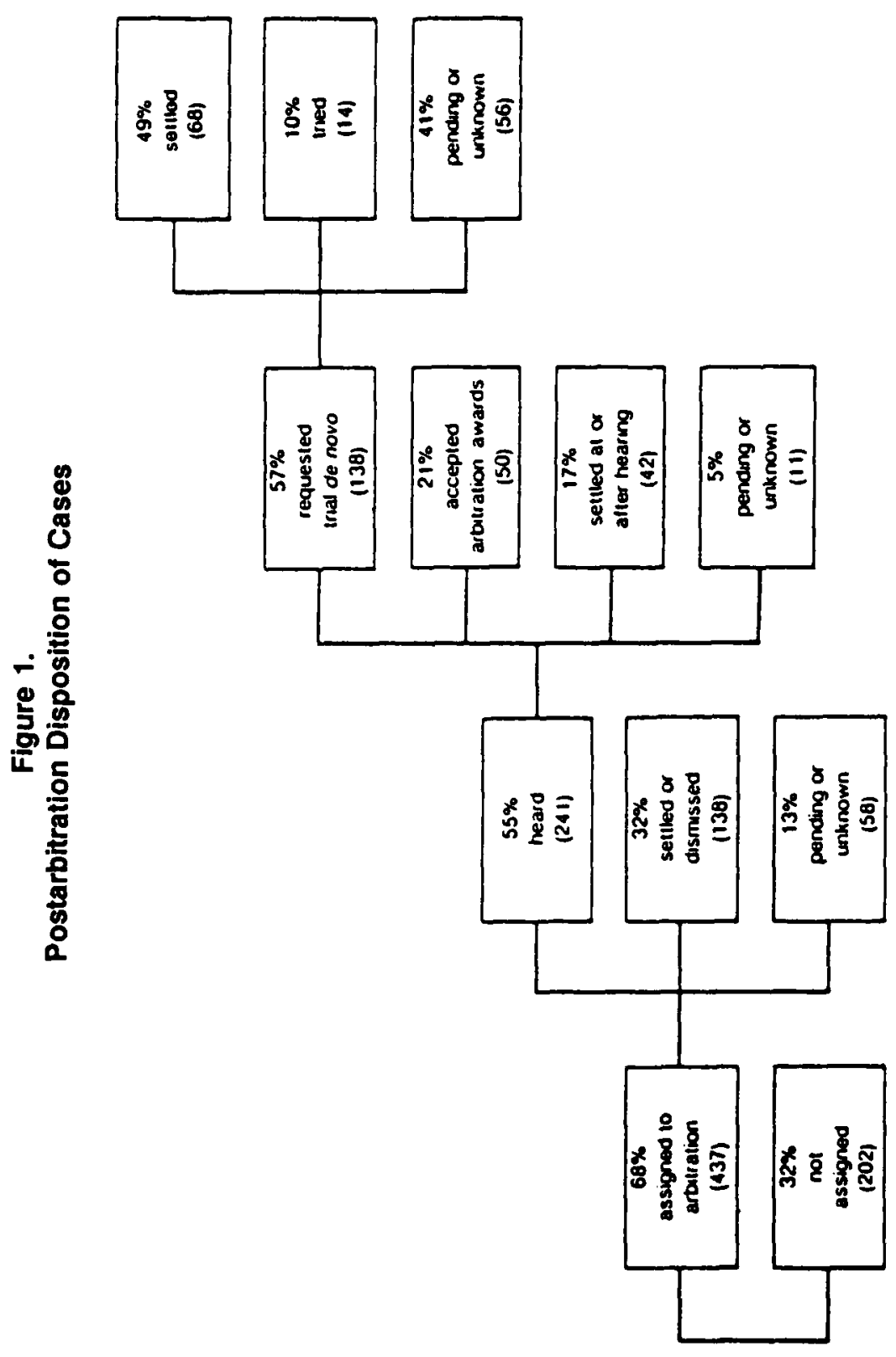

236 
Table 2.

Effects of Arbitration Program on Trial Rates

Trials per

auto filings

$1983 \quad 1985$
Trials per answered cases in 1985 sample*

Unassigned Assigned

$\begin{array}{lllll}\text { Unadjusted sample } & 3.7 \% & 2.3 \% & 5.0 \% & 3.7 \% \\ \text { Adjusted sample** } & 2.8 \% & 1.6 \% & 2.9 \% & 3.7 \%\end{array}$

* Only answered cases were assigned to arbitration program.

** Cases terminated within 80 weeks of filing.

If the arbitration program is diverting cases from the trial calendar, one might expect unassigned cases to be more likely to proceed to trial than cases that are assigned to the program. In Table 2, we also estimate the 1985 trial rate separately for assigned and unassigned cases. Since only answered cases were assigned to the program, we estimated trials per answered cases. As with the pre-post comparison, we were unable to detect a statistically significant reduction in the trial rate as a function of assignment to the arbitration program. There is an apparent reduction when one uses the unadjusted sample, but this pattern is not significant. ${ }^{13}$ The trend for the adjusted sample is in the opposite direction, but this pattern is also nonsignificant.

In sum, our trial rate estimates do not confirm the expectation that arbitration would divert cases from trial, although our sample is too small to detect a decrease in the trial rate of only one or two percentage points. A sample large enough to permit more definitive conclusions would not have been feasible without a considerably more costly data-collection effort. Of course, the fact that trial rates in New Jersey were already quite small does not mean that further

13 We would have required over 7,000 cases in our 1985 sample alone to conclude that an effect this small is statistically significant. 
reductions would be trivial. Indeed, they might result in fairly substantial reductions in judicial workload. Whether such reductions would achieve a net savings in public costs depends on whether they would offset the expense of providing arbitration hearings.

Effects on Bilateral Settlement Rates. Although we were not able to detect a reliable diversion of cases from trial, our data do demonstrate a fairly dramatic diversion of cases from private, bilateral settlement. This change is demonstrated in Table 3.

Table 3.

Effects Of Arbitration On Terminations

Prior to Third-Party Hearings*

\begin{tabular}{lccc}
\hline & 1983 & \multicolumn{2}{c}{1985} \\
& All Cases & Unassigned & Assigned \\
\hline Unadjusted sample & $77 \%$ & $63 \%$ & $32 \%$ \\
Adjusted sample** & $92 \%$ & $97 \%$ & $45 \%$ \\
\hline
\end{tabular}

* Percentage of contested cases settled or dismissed prior to arbitration or trial.

** Cases terminated within 80 weeks of filing.

As with our trial rate estimates, we computed preadjudication disposition rates using both the unadjusted and adjusted samples. The same pattern emerges in both analyses: Cases assigned to the program are significantly less likely to settle without third-party adjudication, and the effect appears to be quite large. This effect is not unique to the New Jersey program, but has also been observed in North Carolina at both the state (Clarke, Donnelly, and Grove, 1989b) and federal levels (Lind, 1990), and at the municipal level in Rochester, New York (Weller, Ruhnka, and Martin, 1981). ${ }^{14}$ Thus, arbitration programs provide informal

\footnotetext{
14 Note that both of the North Carolina studics replicated this effect using randomized field
} experiments. 
third-party adjudication for many litigants who would otherwise have reached a private bilateral settlement or permitted their cases to be disposed of by default or dismissal.

Effects On Time To Disposition. When an arbitration program diverts more cases from bilateral settlement than from trial, there is little reason to expect it to accelerate the average pace of litigation. And indeed, when we examined the average time taken to resolve auto negligence suits, we found that after arbitration was introduced in New Jersey, auto negligence suits actually terminated more slowly.

During the first 80 weeks after filing, cases assigned to the arbitration program took significantly longer to terminate than comparison cases $[F(2,487)=38.68$, $p<.0001$; Tukey post-hoc contrasts, $p<.05]$. On average, the time between case filing and final disposition was 409 days for cases assigned to the program, but only 306 days for the prearbitration cases and 307 days for cases filed in 1985 but not assigned to the program. Among the cases that were assigned to the arbitration program, cases terminated more slowly if they received a hearing (mean $=423$ days) than if they settled without a hearing (mean $=366$ days) $[t(177)=-2.63, p<.01]$. However, the assigned cases that settled without a hearing still terminated more slowly than unassigned cases that settled (mean $=315$ days) or prearbitration cases that settled (mean $=290$ days) $[F(2,309)=12.96, p<.001$; Tukey post-hoc contrasts, $p<.05$.].

Figure 2 shows the cumulative termination rate for each month after filing. For example, the figure shows that up to six months after filing, approximately 22 percent of the cases in the 1983 sample had terminated. ${ }^{15}$ A comparison of the three lines on the figure indicates that cases that were filed in 1985 but not assigned to arbitration terminate at about the same rate as cases filed in 1983, before the program was initiated. However, cases assigned to the program are clearly terminating at a much slower rate, especially in the early months after filing. For example, just under two percent of the assigned cases had terminated within six months after filing.

15 The horizontal axis of the figure terminates at 18 months; as described above, this cutoff point controls for the pending cases in the 1985 sample. 
Figure 2.

Cumulative Termination Rate

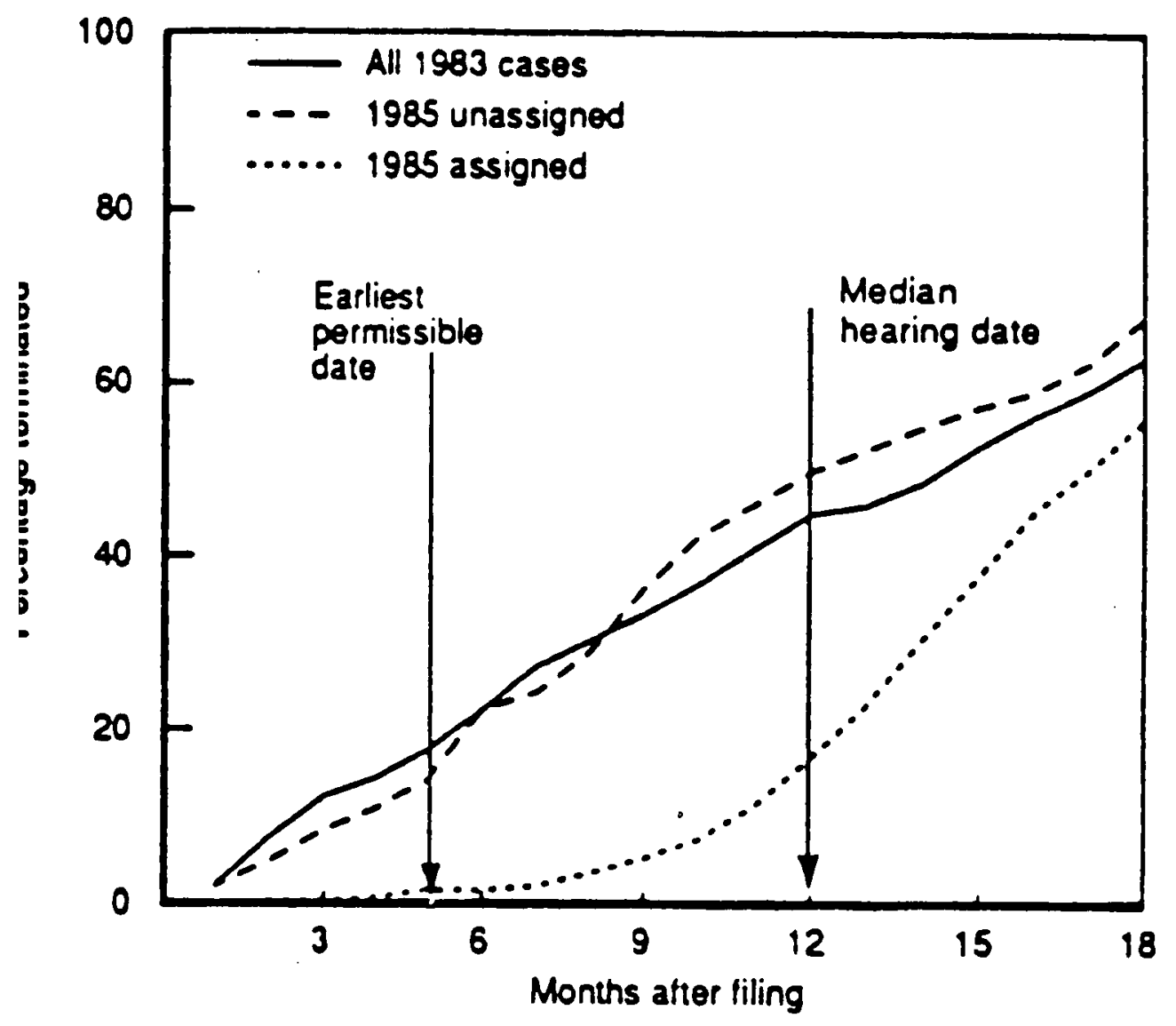


Apparently, disputants who were provided with the option of arbitrating their case chose to wait for a hearing rather than enter into early settlement negotiations. Although some of these cases still settled before the hearing, settlement negotiations may have been postponed until the hearing date approached, and many cases didn't terminate until after the hearing took place. As a result, to the extent that there is a delay in scheduled hearings, we would expect cases assigned to the program to take longer to terminate, even if they settled without a hearing.

Two pointers have been superimposed on Figure 2 in order to help explain the observed pattern. The pointer on the left highlights the earliest permissible date at which an arbitration hearing can be held, as mandated in the program rules (see MacCoun et al., 1988: Appendix B). The pointer on the right highlights the median hearing date for arbitrated cases in our 1985 sample, almost 12 months after filing. Note how the assigned cases begin terminating much more rapidly after this point, nearly catching up to the unassigned and prearbitration cases by the 18-month point.

This pattern suggests that the New Jersey courts might dispose of assigned cases more rapidly by scheduling earlier arbitration hearings. There is a six-month gap between the earliest permissible hearing date and the median date for actual hearings, during which assigned cases terminate very slowly. If the courts and disputants can shorten this gap, it seems likely that arbitration cases will terminate more rapidly. In support of this argument, the number of days from filing to hearing and from filing to termination for assigned cases are positively associated $[r(161)=.56, p<.001]$. In other words, cases that get early hearings terminate more quickly. Also, across the eight courts we studied, we found that on average, courts scheduling earlier hearings terminated cases more rapidly [Spearman's rank order correlation $=.64$ ].

Although the arbitration program apparently increased the average amount of delay in disposing of cases, this does not mean that it took longer to arbitrate a case than to take it to trial. Among the assigned cases in our postarbitration sample, trial was a significantly slower mode of disposition (mean $=502$ days from filing) than arbitration (mean $=404$ days), prearbitration settlement (mean $=390$ days), or postarbitration settlement (mean $=428$ days) $[F(3,242)=5.17, p<.005$; Tukey post-hoc contrasts, $p<.05$.] Thus, an arbitration program can make a trial court less efficient even when the arbitration procedure is more efficient than trial. 
This pattern only seems paradoxical when we forget that absent arbitration, most cases would be resolved by settlement, not trial.

\section{Discussion}

In summary, our evaluation suggests that the New Jersey Automobile Arbitration program has indeed provided "alternative dispute resolution," but as an altemative to bilateral settlement, not to trial. Because disputants apparently postponed settlement while waiting for hearings, the program appears to have added significantly to the amount of time it takes to resolve auto negligence cases in New Jersey. This is clearly not the effect the program's creators envisioned.

Nevertheless, I believe it would be a serious mistake to conclude that the arbitration program is a failure, for two reasons: (1) the increased inefficiencies were by no means inevitable - and are probably correctable, and (2) the same behavioral dynamics that helped to undermine the program's efficiency objectives illustrate how well arbitration fulfills another objective: providing greater access to fair and impartial third-party adjudication. I elaborate on each argument below.

Efficiency as an objective. There are reasons to expect that an arbitration program can meet some of its efficiency objectives at the aggregate level. Other arbitration programs appear to have achieved reductions in trial rates, time-to-disposition, and/or costs (e.g., Barkai and Kassebaum, this issue; Clarke et al., this issue). And our evaluation has identified some areas of leverage in the New Jersey program for bringing about greater efficiency; e.g., scheduling earlier hearings. We also found that prescreening for eligibility reduced the proportion of filings assigned to the program as well as the trial de novo demand rate. Of course, if courts were to develop prescreening procedures that could predict whether a case had a high or low probability of trial, they might be able to systematically divert cases from the trial calendar without affecting bilateral settlement rates. But to my knowledge, adequate prediction methods are not available (cf. Priest and Klein, 1982).

Access as an objective. Even if an accurate "screen-and-divert" strategy of screening out "settleable" cases could be achieved, it would undermine what I believe is arbitration's greatest asset: its success in meeting the demand for third-party adjudication. Our post-hearing survey (MacCoun et al., 1988), like other available surveys (Adler, Hensler, and Nelson, 1983; Clarke et al., 1989b; 
Lind, 1990; Lind et al., 1989), indicate that litigants evaluate arbitration hearings quite favorably. And their attorneys were, if anything, even more favorable.

Moreover, in another recent survey of tort litigants in three different state court systems (Lind et al., 1989), we found that litigants evaluated both arbitration and trial-but not judicial settlement conferences-quite favorably, and for similar reasons. Both trial and arbitration were seen as providing unbiased, respectful, dignified treatment-qualities that litigants valued. Litigants also valued the adjudicative aspects that arbitration shares with trial- an opportunity to "tell their side of the story," and to receive a third-party judgment that is based on the merits of the facts and law pertaining to the dispute. ${ }^{16}$ Importantly, we also found that litigants' evaluations of procedures were much less sensitive to the objective delays and costs they incurred than is often supposed (see Lind et al., 1989).

Our evaluation demonstrates that there is no guarantee that arbitration programs will make courts more efficient in expediting the civil caseload; as in New Jersey, there is a risk that arbitration can even prolong disputes. Nevertheless, the growing body of evidence suggests that litigants may be willing to accept this price in order to benefit from the third-party adjudication that arbitration provides.

16 In the New Jersey post-hearing survey (MacCoun et al., 1988), 62 percent of the litigants endorsed "telling my side of the story" as their most important objective; by way of comparison, only 18 percent endorsed "help reach a compromise with the other side." We also found that awards were seen as significantly less fair if the arbitrators were seen as simply "splitting the difference," rather than basing the decision on the facts and the law. 